\title{
Reading Models: A Review of the Current Literature
}

\author{
Dr. Osama Abu Baha \\ Newcastle University-UK \\ University College of Educational Sciences-Palestine \\ International Islamic University -Malaysia
}

\begin{abstract}
Reading is not only how to read a piece of literature, a book, a story ...etc., but it is also how to acquire the meaning and the implications through reading. It's the role of parents and pre-school teachers to help the child acquire good habits to be ready to master the reading skills. This paper aims to review the three types of reading models. It is also intended to explore the different types of reading strategies and the different approaches that are used in teaching these strategies. Then more focus will be over-highlighted on how to deal with reading comprehension difficulties. These points are supported by certain activities that would be beneficial for stakeholders, teachers and learners of English as a second language. One should be aware of what kind of texts he/she is offering to his/her learners. Texts should be authentic or simplified according to the students' levels, ages and needs.
\end{abstract}

Keywords- reading, comprehension, models, approaches, strategies.

\section{INTRODUCTION}

The question of how teachers should teach reading may be one of the most important topics in the field of education. If teachers want their students to learn to read well, they should find a way to encourage them to read for knowledge and pleasure simultaneously. This essay will spotlight the reading skills and how it should be taught in integration with other skills such as listening, speaking, and writing. If the skills were divided into fragments, the text would lose its meaning, coherence, and unity. Therefore, teachers are not advised to teach reading in isolation of its practice in authentic situations. Furthermore, the reading skills are so significant to the whole process through acquiring listening, speaking and writing skills. Reading is the power of words as (Cook 2001) says, 'it's the words that you feel you struggle for rather than the grammar or pronunciation...reading, like speaking, occurs in a context rather than in isolation. The meaning of a text is not found just in sentences themselves, but is derived from the previous knowledge stored in the reader's mind.'

It's obvious that before teaching reading, the students of a special level should have acquired some skills which enable them to read fluently. For example, they should know the rules which govern the way the letters are pronounced and arranged into words. Don Drummond (1979) identified that the child pass through three distinctive stages in acquiring reading which enables $\mathrm{him} / \mathrm{her}$ to read competently. These stages are readiness, dependency, and independency.

It's the role of parents and pre-school teachers to help the child acquire good habits to be ready to master the reading skills. Within the next few years in school, the child becomes dependent on his teachers whom through the passage of time adjust this dependency into independency and creativeness.

Reading depends on words which are structured into sentences. Reading is not only how to read a piece of literature, a book, a story ...etc., but it is also how to acquire the meaning and the implications through reading. Neither, it is a matter of imitation or repetition but it is also how a student could seek knowledge, pleasure, and practice and how he could fulfill his needs as well. Carrilo (1976) argued that 'Reading is not something that happens to you automatically when you arrive a certain chronological age. Reading may be acquired at many stages of growth and development. Reading is a combination of mechanics, understanding, retention, and use.'

Hedge (2000) explained that learners should be aware of six types of knowledge to assist them make sense of what they read. Syntactic, morphological, general world, sociocultural, topical and Genre knowledge are integrated while reading.

In this review, different approaches of teaching reading will be discussed. The bottom-up, the top-down, and the interactive models will be explored. Second, some techniques in teaching reading will be tackled in such as experience method, look and say method, the phonic method, and the audio- visual method. Fourth, how the alphabet, vocabulary, and comprehension should best be taught will be elaborated. Next, a look at the contemporary trend of teaching reading (the IELTS British Council Exam) will be highlighted. 


\section{MODELS OF READING}

According to Browne (1998), there are three major models of reading which are the bottom-up, top-down, and interactive models.

\section{The bottom- up model}

According to Browne (1998), this model describes reading as a process that starts with the learner's knowledge of letters, sounds and words and how these words are formed to make sentences. This model is called part to whole model because it goes from partial to whole knowledge. This model is so effective in the early childhood, especially students as young learners. It's effective because the emphasis here is on the letters, recognition of their shapes and reading individual words. However, this model has many disadvantages if used for higher levels since it forgets the reader's expectations, experience, and attitudes. Furthermore, it doesn't pay attention to the context since it only encourages remembering.

\section{The top-down model}

This model, which is also called inside-out model and whole to part model, involves the reader's experience and what he/she brings to the reading material. Browne (1998) clarified that, 'this model suggests that readers begin to read by drawing on what they know about the structure and the meaningfulness of language, the structure of stories and other genres and their knowledge of the world to predict the general meaning and specific words in context.'

This model is broader and more realistic. It should be pointed out here that whenever the experience of the students is being involved, the more effective the teaching will be. Moreover, this model encourages guessing. However, one of its disadvantages is that cross-cultural identifications might play a major role in recognizing such texts. For instance, some cultures might lack information about certain topics and readers could face great difficulties in recognizing what the topic is about.

\section{The interactive model}

Stanovich (1980) argued that this model gathers the features of the bottom-up and the top-down models and gives reading more meaning. Here, the readers are more involved in reading. They use their knowledge of subject theme, their pre-experience of written words, their reading and their own expectations to make predictions about the reading text. So, the textual details are the best way in the recognition of the words and the letters the text contains.

The most important advantage of this model is that the communicative activities and the reading skills are integrated. In my opinion, if we were allowed to do so in Palestine, we would adopt this model, simply because it is more realistic and enjoyable to all kinds of students. Moreover, whenever the students' experience is involved, the more interesting, thrilling and lovely the reading will be.

\section{Reading Strategies}

It's very important to point out that there are many strategies in reading such as skimming, scanning, and reading for details. Pugh (1978) and Lunzer and Gardner (1979) as cited in Hedge (2000) described various strategies of reading.

Receptive Reading:

It's reading a story or a newspaper article for joy and fun. Reflective Reading:

It's reading a text and then, rereading by backtracking for checking.

Skimming:

It's the strategy in which the learner is being exposed to a reading material that he/she is not sure or certain what it is about. Here, the learner looks for key details only.

Scanning:

It's the strategy in which the learner is being exposed to a material that he/she has some information about it. Here, the learner looks for certain information.

Reading for details( intensive reading):

The learners read carefully to find out exact information.

\section{METHODS OF TEACHING READING MATERIAL}

\section{The Experience Method}

Carrillo (1976) showed that, 'in this method, the teacher uses the experience or the background of the students' interests to produce reading material with which to teach.'

Here, the teacher involves the students in a discussion orally and at the same time he writes on the board some of what they have been interacted in. Later, he teaches them a reading passage of their own production. One of the advantages of this method is that the students produce a passage that meets their interests. In addition, it should be added here that the meaning of the passage is understandable, the content is flexible and all students take part in presenting their own ideas with the result that individual differences are taken into consideration. However, some disadvantages could be tackled in. One is that, literary quality isn't so high. Secondly, the organization and the sequence of sentences may be weak and poor.

The Look and Say Method versus the Phonic Method Look and Say method isn't new but it still has great effectiveness inside the classroom and is taught in integration with listening and speaking skills. Students are 
taught by displaying a picture and say what the picture is about. "Here, they learn the words before learning the sounds). This method is negating the old Phonic method which was used to focus on sounds that can be used for recognizing new words. Howard (1971) argued that 'the available evidence on word attack instruction indicates that greater positive transfer (i.e. Ability to read new words composed of familiar grapheme-phoneme correspondences) results from single letter training than from whole -word training....

In brief, the Look and Say method is fruitful for beginners (normally kindergartens); since it only focuses on memorization. Alternatively, the phonic method begins with teaching the sounds blended with the letters. It should be advocated that the phonic method enables the reader to decode the written sounds. One major point to comment on is that nowadays there is a great trend to return to the phonic method because sounds should be presented and heard before the letters are displayed as Cook (2001) noted. Moreover, some words such as "truth" can't be displayed as a picture and so how a teacher could teach this word by look and say method.

\section{The Audio-Visual Method}

This method was firstly developed by Glenn McCracken after some experiment in Newcastle, Pennsylvania. This man used coloured filmstrips of one of the textbooks. The content of the filmstrip is not necessarily the same of the text. Then, he projected images of the reading lesson. This method is a mixture of "look and say method" and the "phonic method". Alternatively, teachers could blend the two methods where necessary to teach the young learners.

In my view, this method has many advantages. The students pay more attention; and the large coloured projection is nice and thrilling in the dark classroom away from distraction. Moreover, Smith (2004) insisted on its advantages saying that reading would be incredible within the lack of visual information through which the brain can handle things more easily at any time.

Here, it's very fundamental to say that the audio-visual method has taken many forms through the $20^{\text {th }}$ century. It's not limited to videos, or filmstrips since computer assisted media are used to produce special audio-visual programmes. Wideatt and Hardisty (1989) suggested new creative applications for language analysis such as exploitations of general purpose software as processors and spreadsheets. Moreover, it should be added that if the students take part in the production of the audio-visual means: by acting, shooting, and presenting, lessons will be more enjoyable and beneficial.

\section{Reading through Play Approach}

Baker (1980), in his book, "Reading through Play", showed the teachers and the parents how to help their children learn to read by playing structured games.

In his development, the child needs many kinds of plays in order to fulfil his/her needs and concerns. By playing, the child will be able to discover a solution to a question and learn about his/her surroundings.

Baker (1980) pointed out that the child will be able to read through play if he can, '.....pronounce words fairly clearly; speak in sentences; enjoy stories, poems and songs; remember and repeat simple rhymes and songs; understand and carry out simple instructions; tell a very simple story; recognise shapes and pictures and play constructively....

It is worth to add that the child should also learn the importance of the team and cooperative work. In reading through play, students can use different varieties of games such as rhymes and poems, odd one out, find the difference and memory games. Briefly, these reading mechanisms will be elaborated.

\section{Rhymes and Poems}

The teacher discusses what he means by rhyme. Then, he gave an example of rhyme, such as the poem:

Busy curious thirsty fly,- Drink with me and drink as $\underline{I}$

Freely welcome to my cup-.Drink with me and sip it up The teacher repeats the rhyme until the child commands it. After that, the teacher intentionally makes errors in the rhyme so as to check if the student can do the correction. To fulfil their needs, the teacher can ask them to collect some poems of their interests and read them for pleasure because this will enhances their reading abilities.

\section{The odd one out}

Here, the teacher arouses the students' awareness towards reading by listing some words with a strange word among them. This task is conducted within a game. For example, the teacher writes without reading:

\section{Learn burn turn horn \\ Write mist fight side \\ Peak beat heat hat}

The students read the words and find out the odd ones. Later, they were asked to make collections of what they were interested in so that they could elevate their reading for rhyme.

\section{Find the differences}

This activity could be used to elevate the students' awareness towards the environment which is a very important topic in our lives. First, the teacher shows the students two different pictures: one is about a rural life and another about the urban life. Here, students can write and read what they have learnt. A smart teacher can ask more environmental questions at the end of the task.

\section{Memory Game}

Teachers can place several toys in front of the boy. Then, 
they ask the students to close their eyes. The teacher removes one of the toys. Students are asked to reopen their eyes and identify which one has gone. Students can change roles. By this, reading from memory is enhanced. To sum up, reading through play is a very broad subject, and one can't cover all of its aspects. But, it should be noted that the major advantages of this approach are the collaborative work and the high- lightened interest in the lesson. One of the disadvantages of this approach is that students become so dependent on their teachers; and teachers might face problems in the control of their classrooms especially in over- crowded classrooms such the refugees' camps in Palestine.

\section{TEACHING THE ALPHABET AND THE VOCABULARY}

The first step in teaching reading is the alphabet. Roberts (1990) indicated that if young learners were able to learn the alphabet off by heart and master it by special songs or other mechanisms, they would absolutely be good readers in their future studies. When teaching vocabulary, teachers should employ flexible strategies in word recognition. Moreover, they have to teach vocabulary into context and ask students to guess tricky meanings or new taught words. Furthermore, it should be emphasized that words must be heard before writing. It's important that words should be put into real life and authentic situations. Cook (2001) indicated that it would be better for young learners to organise their vocabulary into groups in their minds to make it easier for them to remind which lexis will be helpful in their reading.

Early from the beginning, student should acquire some rules of the vowel and consonant systems in English which is a very vital step in teaching reading skills. It's very valuable if, after teaching the vocabulary, students are asked to prepare a photographed dictionary of newly taught words. Each student should bring a picture representing each word, write a meaningful sentence about it and read it for pleasure. This mechanism enhances self-independence and reduces the concentration on the dictionary. Jenkinson (1973) supported the idea by noting that, 'frequently, learning how to use a dictionary is left to trial and error, with the result that the reader rarely uses a dictionary since he finds it difficult and unsatisfactory, and because it often interrupts the flow of his reading.'

Teaching vocabulary is an enormous issue to cover. However, it should be noted that learners have to be aware of the energy of their competence. Aaron and Joshi (1992) has discussed the semantic -maps by indicating that students, in their attempt to strengthen their reading, may choose a word or a topic and draw a tree of many branches and try to think of possible words related to the main concept (the target word). Later, the learner could think of some systematic ways to link these words such as antonyms or synonyms.

Games are also very important in teaching vocabulary. In a current study, Torgesen (1992) found that learners can significantly improve their reading using Daisy or Castle Quest. These games can enhance the skills of word recognition and simultaneously can higher their achievement in the reading skills. The role of the parents mustn't be ignored on the teaching of reading and how effective they are in acquiring new words to their children. A psychology Professor called Ann Evans says, 'we found that parents who engage their kindergartens or pre- school children in activities with alphabet books, letter sounds, spelling, and printing are initiating a process that will lead to their children having improved levels of reading.'

\section{STRATEGIES IN IMPROVING READING COMPREHENSION}

There are many strategies to improve the reading comprehension. However, students should have mastered some vocabulary according to their levels. Teachers should be aware of giving their students reading comprehension that suits their abilities. One of the oldest and functional strategies is silent reading. This kind of reading has two aims. One is to uncover the main idea through skimming and the other is to find out the major details through scanning. Moreover, the reader should be aware of the organisational pattern of the reading passage: narration, contrast, analogy, cause-effect, chronological,.....However reading aloud is discouraged by many researchers such as Cross ( 1995) who supported his idea arguing that, " reading aloud is not a real life skill; when one student reads aloud, the others are inactive; reading is stopped for mistakes; the reader's attention is on pronunciation not meaning.'

The major thing in teaching the reading comprehension is to develop the critical thinking of the reader as Aaron and Joshi (1992) who noted that one part of successful reading comprehension is by developing critical thinking for readers in order to be able to break up facts of the reading passage from their main views and opinions.

The key question is what steps should be used in teaching reading comprehension. Through certain observations, the reading passage should be best taught by using many procedures. In the Palestinian Curriculum (1988), there is a passage about (Floods in Bangladesh) (See scanned Passage in appendix A) prepared for ninth grade .According to the Teacher's Book, certain steps should be used in teaching the passage. Firstly, the new learning 
should be linked with the students' previous knowledge by asking some general questions about water, rain, weather, mountains, snows, etc. Second, Students are asked to look at the map to identify the location of Bangladish in order to enhance the geographical background of the students. Next, they are asked to look at the big picture of the reading passage and to give answers about short questions. Some of these questions should stimulate their thinking such as:

Whom do you see in the picture?

What's the weather like?

What's the woman carrying?

What happened to her house?

It's raining, but why is he wearing a T-shirt?!!!

What are the names of the two rivers in Bangladish?

Who describes the picture by (his\} own words?

After that, students are asked to read the passage silently, underline the difficult words (trying to infer them from the context), and then underline the major ideas as well. Then, by group work they are asked to compare the ideas of the reading passage together. Next, each group have to summarize and paraphrase the reading passage. Near the end, a summary of the lesson is made by answering the discussion questions. Finally, as homework, students are asked to read something about floods in other areas of the world to enhance self-reading. This mechanism is supported by Bielby (1998) in which he indicated that the literal level of the reading comprehension should be highlighted. Learners should recognize words so quickly in their working memory in order to be good readers. In addition, Hedge (2000) has clarified that, in teaching comprehension, we should follow certain steps within a mechanism called SCROL summarised from Grant (1993) who maintained that, ' first teachers and students should survey the headings, connect the headings to each other, read the text for details and ideas, outline the major ideas and supporting details, and finally look back to the text and check the accuracy of the major ideas and details that you write'.

\section{EXTENSIVE READING, TO DEVELOP THE READING COMPREHENSION}

Students read to get information, to have pleasure, to practice their language and to learn language. Therefore, students may read their texts as the main source of information. But, teachers should encourage other reading materials such as notices, magazines, journals, newspapers, forms, books, e-mails and advertisements. Students can skim, scan or intensively read any of these using their syntactic, morphological, socio-cultural, topical, or genre knowledge they obtain. So, one way to enhance reading is by directing students to extensive reading. There is no exact definition for this term, but in general (Hedge 2000) characterized the extensive reading that includes the following, '.reading large quantities of short stories, novels magazines............reading consistently over time on a frequent and regular basis .........reading longer texts than usual.........reading for general meaning, primarily for pleasure, curiosity, or professional interest... ......reading longer texts during class time but also engaging in individual, independent reading at home, ideally of self-selected material.

The best activity to show how the extensive reading works is by looking at the (IELTS) exam which represents the International English Language Testing System. This test is recognised by British universities as basis of accepting non-native language speakers. This test contains reading material of different levels. The reading, here, is best be taught by nine criteria as the web- site of Holmesglen Institute of TAFE in which Bruce Mackenzie, director of this Institute, pointed: if someone wants to prove his reading he should master several skills such as summary completion, matching headings to paragraphs, multiple choice, selecting factors, table completion, matching discourse, sentence completion, short answer questions, labelling diagrams and classification.

To sum up, extensive reading can be conducted for all ages and levels. Even, slow learners can find a good opportunity to overcome the individual differences and to master a good progress of reading that might be of their interests outside the classroom. Moreover, teacher should bear in mind that extensive reading develops the critical thinking of the students since acquiring such knowledge enhances their abilities through linking previous knowledge with new learning.

\section{CONCLUSION}

Whether you are teaching in a refugee camp, a village, a city or whether you are teaching in a poor, developing or a modern civilised country, students are nearly the same. We devote ourselves to carry this sanctified message; and so it should be carried out accurately. You should be acquainted with what fulfil their interests and meets their needs. The four skills are integrated and can't be taught separately; and if I have already discussed the reading skill, it must be noted that this was only for the sake of the study.

You should be aware of what kind of texts are you introducing to your learners. Texts may be authentic or simplified according to your students' levels, ages and needs. However, don't forget to specify the length of the texts accordingly. In addition, don't forget to encourage your students to read a diversity of textbooks inside and 
outside the classroom in order to enhance their critical thinking and to widen their knowledge in all subjects'

The students consider their classroom to be their own world. Even parents have little effect on their children and it seems that you, as a teacher, could mould your students to be active readers. Early from the beginning; don't forget the alphabet songs; don't forget the thrilling sounds and words done by you; don't forget enhancing them to investigate their own world through bringing tales and directing them to extensive reading; don't forget that the end of the tale or the story could be a good source to elevate your students' imagination; don't forget to enhance their reading by acting stories; don't forget that "errors are inevitable" and play a positive part in your feedback.

\section{ACKNOWLEDGEMENTS}

Thanks for Allah (SWT). Glory and satisfaction to Our Prophet Mohammad (PBUH).

\section{REFERENCES}

[1] Aaron P. G., Malatesha R. Joshi (1992) Reading Problems: Consultation and Remediation. New York: Guilford Press, pp 158, 167

[2] Baker, Carol (1980) Reading Through Play: the Easy Way to Teach Your Child. London: Macdonald Educational Ltd. PP6, 22, 24, 26.

[3] Bielby, Nicholas (1998) How to Teach Reading: A Balanced Approach. Lamington Spa, England: Scholastic Ltd., p. 129.

[4] Browne, Ann (1998) A Practical Guide to Teaching Reading in the Early Years. London: Paul Chapman Publishing Ltd. p. 9

[5] Carrillo, W. Lawrence (1976) Teaching Reading: A handbook. New York: St. Martin's Press, Inc. P. 19

[6] Cook, V. J. (2001) Second Language Learning and Teaching (3rd ed.)London: Hodder Arnold. .PP. 69, 89

[7] Cross, David (1995) A Practical Handbook of Language Teaching. Hemel Hempstead, Hertfordshire, England: Phoenix ELT p.80

[8] Drummond, Don, Edna Wignell (ed) (1979) Reading: A Source Book. London: Heinemann Educational Books. p. 2

[9] Ellis, Gail\& Barbara Sinclair (1989) Learning to Learn English: A Course in Learner Training. Cambridge: Cambridge University Press.

[10] Hardisty, D, Scott Windeatt (1980) CALL. Oxford: Oxford University Press.

[11] Hedge, Tricia (2000) Teaching and Learning in the Classroom. Oxford: Oxford University Press, pp 196-200.
[12] Holmesglen Institute of TAFE. The Reading Components of the IELTS Test.( Retrieved from http://international.holmesglen.vic.edu.au/ieread.htm

[13] Howard J. Sullivan, Masahito Okada, Fred C. Niedermeyer

American Educational Research Journal, Vol. 8, No. 2 (Mar., 1971), pp. 227-239

[14] News Release (2000) Canada: Communications and Public Affairs, University of Guelph (Retrieved from

http://www.uoguelph.ca/mediare/archives/001211.ht $\underline{\mathrm{m}}$

[15] Roberts Geoffrey R. (1999) Learning to Teach Reading. London: Paul Chapman Publishing Ltd, p.9

[16] Smith, Frank (2004) Understanding Reading: A Psycholinguistic Analysis of Reading and Learning to Read. New Jersey: Mahwah, N.J. : L. Erlbaum Associates, p. 75.

[17] Staiger, Ralph C. (1973) The Teaching of Reading. Paris: International Reading Association, UNISCO: Xerox Education Company-Lexington, p. 44

[18] Stanovich, K (1980) Towards an Interactive Compensatory Model of Individual Reading Differences in the Development of Reading Fluency. Reading Research Quarterly, vol. 16, no. 1, pp 32-71

[19] Torgesen, Joseph K. (1995) Computers as Aids in the Prevention and Remediation of Reading Disabilities. Learning Disability Quarterly, Vol 18, no. 2 , pp 76-87 ( Retrieved from http://chd.gse.gmu.edu/chdinfo/read.htm 